\title{
Switching to L1 in the EFL Classroom-the Perspective of Adaptation
}

\author{
Liu Jingxia* \\ English Department, College of Foreign Languages, Three Gorges University, China
}

\begin{abstract}
Verschueren's Linguistic Adaptation Theory (1999) provides the theoretical framework for the study on codeswitching in EFL classroom. It views code-switching as an adaptive phenomenon in the interaction between people and their conditions of life.

Based on Verschueren's Linguistic Adaptation Theory, the present paper gave a qualitative analysis of the adaptability that teachers' code-switching to L1 can fulfill. The objects to which teachers' switching to L1 adapts were classified in relation to linguistic reality, teachers' and students' language proficiency, and communicative needs. The data for the study were collected from classroom recordings in EFL classes of Three Gorges University of China. The audio recordings of the teacher talk were transcribed and analyzed for how teachers' code-switching to L1 adapts to linguistic reality, teachers' and students' language proficiency, and communicative needs. It was found that teachers' code-switching to L1 is a realization of teachers' adaptation to communicative goals in EFL classroom.
\end{abstract}

Keywords: Teachers' code-switching to L1, adaptation, linguistic reality, teachers' and students' language proficiency, communicative needs.

\section{INTRODUCTION}

Code-switching (CS) refers to the alternating use of two or more languages by bilingual or multilingual speakers within one conversational episode, either in the same conversational turn or in consecutive turns [1]. It is a conversational strategy used to establish, cross or destroy group boundaries; to create, evoke or change interpersonal relations with their rights and obligations. As the natural phenomenon of language communication, CS has been one of the focuses in the field of linguistic research. Linguists and educators, such as Poplack [2], Auer [1], Cook [3] either have made their studies on CS as a general phenomenon or narrowed their research when it appears in a specific context, for example CS in the classroom. They have developed the study of CS by different approaches, that is, the sociolinguistc approach, the psycholinguistic approach, and/or the pragmatic approach. Within these subfields, the pragmatic approach is a fresher perspective in which the analysis of CS has simultaneously involved social, communicative, psychological and linguistic factors in a dynamic context. CS used by communicators will take various functions in different contexts among which teachers' CS in FL classroom is a very important realization.

For the current research, we attempt to explain why teachers' CS to L1 happens in EFL classrooms of Chinese universities on the basis of Verschueren's Linguistic Adaptation Theory (1999) and to reveal the dynamics and functionality of teachers' CS to L1 in the process of teaching in an EFL classroom.

*Address correspondence to this author at the English Department, College of Foreign Languages, Three Gorges University, China;

E-mail: clare04@126.com

\section{RELATED STUDIES}

\section{Verschueren's Linguistic Adaptation Theory}

Verschueren [4] proposed a general framework for the discussion of pragmatics, which is understood as a theory of linguistic adaptation or adaptability. Verschueren noted that, "using language must consist of the continuous making of linguistic choices, consciously or unconsciously" (p.56). He pointed out three hierarchically related key notions in the process of making choices: variability, negotiability and adaptability. Variability is the property of language which defines the range of possibilities from which choices can be made. At any given moment in the course of interaction, a choice may rule out alternatives or create new ones for the current purposes of the exchange. These effects can always be renegotiated, which brings us to the second key notion, negotiability. It is a property of language responsible for the fact that choices are not made mechanically or according to strict rules or fixed form-function relationships, but rather on the basis of highly flexible principles and strategies. Adaptability, the third key notion, is defined as the property of language which enables human beings to make negotiable linguistic choices from a variable range of possibilities in such a way as to approach points of satisfaction for communicative needs and the use of language is a dynamic process of adaptation. The three notions are fundamentally inseparable. Verschueren used the higher-order notion of adaptability as the point of reference in further theory formation and empirical research. Verschueren assigned four angles of investigation in one coherent pragmatic approach to language use: contextual correlates of adaptability, structural objects of adaptability, dynamics of adaptability, and the salience of the adaptability process (p.59-66). These four angles are actually in agreement with linguistic, social, communicative and cognitive elements involved in the dynamic process of language usage. 
Verschueren's Linguistic Adaptation Theory is quite enlightening in providing us with a theory pattern to study code-switching, as it is intended to offer a better answer to the question of what people do when switching codes, or what they do by means of switching codes [5]. In some cases code-switching is the only choice to realize a certain communicative goal since no other linguistic or non-linguistic means can function in the same way or achieve the same communicative effects. This is perhaps where the importance and necessity of studying CS is underlined.

\section{Teachers' CS in Classroom}

The use of native language and target language has been one of the focuses in the study of second language acquisition for several years. The center of majority of the researches is the necessity of the use of L1 in foreign/second language classroom. Guthrie [6] questioned whether the fact that a lesson is conducted entirely in L2 results in greater intake by learners. Skinner [7] argued that exclusive use of L2 is detrimental to the process of concept development by, at times, providing an obstacle to connecting with thoughts and ideas already developed in L1. Hegen [8] justified codeswitching as being a fundamental language skill that needs to be acquired because it is a normal part of interacting in the multilingual context.

Researchers have also made qualitative and quantitative studies on the teachers' CS in FL classrooms to discuss the reasons and functions of CS. For example, Polio and Duff [9] launched a follow-up study to examine when teachers switched to L1 and for what functions. They discovered that the teachers switched to L1 mainly to explain grammar, to manage the class and maintain discipline, etc. They also identified some variables that might have played a role included language type, departmental policy and guidelines, lesson content, materials and formal teacher training. RolinIanziti and Brownlie [10] conducted a quantitative and qualitative analysis of 5 classes in 4 teachers' French class and concluded that code-switching was mainly involved in 3 functions: translation, meta-linguistic uses and communicative uses. When analyzing reasons of teachers' CS, the resarchers have taken linguistic, social and psychological factors into consideration [9, 11-13] Specifically, the socialising role of the teacher, the importance of variation and repetition, and the teacher's linguistic competence and insecurity are the often-mentioned reasons for CS [1, 3, 14, 15].

The research has made great contributions to the studies of CS in classrooms. Benefitting from them, the present paper attempts to analyze CS to L1 as a dynamic process and take linguistic, communicative factors into consideration to explain CS to L1 in EFL classrooms from the perspective of adaptation.

\section{METHODOLOGY}

\section{Method}

The present study was carried out as a qualitative analysis. The study began with the collecting of natural data by conducting recordings in English FL classrooms, then categorizing the data with lingustic features and communicative functions, and finally summarizing the communicative functions of the switching to L1 on the basis of Verschueren's Linguistic Adaptation Theory. The process of analysis in- volves naturalistic, process-oriented observation and can be called a qualitative one. The objective was to enlighten our understanding of code-switching as a specific linguistic and communicative phenomenon.

\section{Data Source}

The data source comes from classroom recordings in English classes in Three Gorges University where the author is teaching. The recordings were used to analyze communicative uses of the switching to L1 in the EFL classroom. Six class periods (45 minutes for each class) for non-English majors were recorded. Why do we specify our study on these classrooms? Nowadays, the majority of English learners are those non-English majors and their aim is to improve their ability of using language to some extent, not to learn linguistic theories. The exclusive use of the target language cannot always be realized in these classrooms, so teachers have to use switching to L1 in their teaching instructions. And six teachers who taught Grade One (the freshmen) and Grade Two (the sophomores) (three teachers from each grade) were randomly chosen for the recordings, as English is offered as the compulsory course only for the undergraduates of Grade One and Grade Two in Chinese universities. The students were randomly arranged in different classrooms of the two grades by the university. The two grades represent a progression of instruction.

In order not to interrupt or give pressure to the teachers and students, and to gain as real materials as possible, an MP3 player was simply placed before the teacher at the beginning of the class period. The author was not present during the recordings.

All the classes share two characteristics: 1) the main language of instruction was English, 2) lesson type is teaching a text (or text analysis) which is the most typical activity for teaching EFL in the Chinese universities. Teaching a text involves introducing any relevant background, explaining the meaning of any new words and analyzing the use of particular vocabulary items, grammatical elements and sentence structures. So the classroom discourse of teaching a text is largely teacher-led.

\section{Data Collection}

Six teachers' classes were audio-recorded over a period of 4 weeks in November, 2007. The teachers were informed that their lessons would be recorded for a study of classroom discourse, and that the study was intended to examine teacher talk in normal content-based classes, and hence no change should be made in their lessons. Of course, the teachers were not informed about the specific aim of the study; thus, their teaching activities were, possibly, the same as in normal classroom discourse when no visitor was present.

\section{Procedures of Data Analysis}

All the recorded materials then transcribed into written form. The calculation of the amount of Chinese/English spoken by the teacher was undertaken by listening to the records. A starting point, where the instructor seemed to begin addressing the entire class, was chosen and counted as 0:00. From then on, every time the teacher switched from English to Chinese was noted. The measurement of CS was under- 
taken only for the teachers' discourse (excluding students' questions and answers).

The six transcripts were used for data analysis. In the interpretation and explanation of the switching to L1, the linguistic, communicative aspects were taken into consideration for this qualitative analysis.

\section{Data Analysis}

Guided by Verschueren's Linguistic Adaptation Theory, we classified the objects to which teachers' code-switching adapts into three categories: linguistic reality, teachers' and students' language proficiency, and communicative needs.

\section{Teachers' Code-Switching to L1 as Adaptation to Lin- guistic Reality}

Lingustic reality is taken to refer to the real existence and the nature of a certain language [12]. The real existence of a language refers to the linguistic elements and linguistic structures of that language [5]. That is to say, every language possesses some specific linguistic existence which other languages do not share. This is one of the important and common motivations or reasons for the occurrence of codeswitching. The real nature of a language refers to the features and properties of those linguistic elements and linguistic structures of that language in its own right and/or compared with other natural languages [5], and more specifically, it refers to the semantic differences between two languages.

Teachers' code-switching as a means of adapting to linguistic reality is that the occurrence of code-switching appears to be motivated by for pure linguistic reasons. A lexical gap is one of the typical examples. A lexical gap results from a lack of semantic congruence between the words in a foreign language and its putative equivalence in the speaker's mother tongue. In other words, code-switching is used because there are lexical gaps and there are no popular translations for some words.

\section{Example 1}

$\mathrm{T}$ : “科举is a very important examination system in the ancient time of China and was prevalent for a long time. A lot of people wanted to get 状元 (first place in the examination), as it could give them a prominent status and large fortune."

“科举”, and “状元” are the peculiar things in the history of China. There are no English equivalents of these two terms. The teacher switched to Chinese so as to be accurate and concise.

\section{Example 2}

$\mathrm{T}$ : "The way of address in Chinese culture is much more complicated than that in English culture. For example, we have forms of address 伯伯 (elder brother of father), 叔叔 (younger brother of father), 姑父 (husband of father's sister), 姨夫(husband of mother's sister), 舅舅 (brother of mother), however, in English, the word 'uncle' includes all of them. As we know, the relationship between people takes up an important position in Chinese society. So Chinese people address each other in different ways in different situations. Can you give more examples of this kind?"

In this example, the teacher introduced the cultural difference between Chinese and English. She switched to Chinese expressions instead of using English, owing to the real- ity that 伯伯，叔叔,姑父，姨夫，舅舅 have no corresponding English translations.

The author found that in the present data, switching to L1 to adapt to linguistic reality often occured when the teachers provided background or cultural information in class. They engaged in code-switching because there is no proper translation in Chinese for certain words, or the translation did not aid students in their understanding.

Adaptation to linguistic reality is the very important category of teachers' switching to L1 and it fills the linguistic gap between TL and L1.

\section{Teachers' Code-Switching to L1 to Adapt to Teachers' and Students' Language Proficiency}

In the classroom, each of the teachers, the students and their interactions plays an important role in reaching the teaching goals. The teachers' language and activities are designed to fit teachers' and students' language proficiency so that successful communications can be achieved [16].

In most situations, teachers' English proficiency is taken for granted. However, the present data show that sometimes teachers switch to Chinese because they cannot express something in English or cannot express something in English clearly.

\section{Example 3}

T: "Class, let's go on to the next paragraph. (Begin to read the sentences in the next paragraph) 'It was not for beasts to fight each other to the finish. It was not even for throwing religious heretics to the lions.' Do you know 'religious heretics'?"

Ss: "No."

T: "That's OK. Let me explain it for you. Er, er... but I don't know how to explain it in English. In Chinese, it's 异教徒.”

Here, the teacher found it difficult to express "religious heretics" in English, and then he turned to the help of the Chinese expression. The teacher's switching to Chinese adapted to his own language proficiency.

Sometimes students' limited language proficiency may also cause the switching to Chinese (L1).

\section{Example 4}

T: "(Read the sentences of a text.) 'Long, long ago there lived a king who was crude and very much like a savage. He had none of the grace and polish of his neighbours. He was a man of great fancies'... Attention, everyone. What does 'polish' mean here? Anyone knows?'

Ss: (silence)

T: “Actually, it also means 'grace', 高雅, 优美.”

\section{Example 5}

T: "The International Herald Tribune is a very famous newspaper in America. Do you know this newspaper?"

Ss: (silence)

T: “It”s国际先驱论坛报。(The Chinese version of the newspaper)" 
In these two examples, without receiving any responses from the students, the teachers realized that the words might not be in the students' repertoire. So they switched to Chinese to adapt to the students' language proficiency.

\section{Teachers' Code-switching to L1 as an Adaptation to Communicative Needs}

Teachers' communicative needs are decided by the communicative or pedagogical goals in the classroom and are related with teachers' spontaneous motives or intentions to reach the goals. The teachers' intentions or motivations influence or even determine not only what to say but also how to say it, namely, how to construct teachers' discourse to realize certain purposes. In this case, code-switching is produced because of communicator-internal reasons instead of language-internal reasons. It is a realization of active adaptation [5]. Several types of communicative needs are possible.

\section{3a) Teachers' Code-Switching to Emphasize some Points}

Important messages can be reinforced or emphasized when they are transmitted to L1 [13]. The present data also show that the use of Chinese can lay stress on some instructions or directing students' attention to important contents.

\section{Example 6}

T: "Let's come to the next sentence. 'Hoping to find a greatly advanced civilization, the Time Traveler sees in the misty, warm air only an ominous, giant white sphinx on a huge pedestal.' 请大家注意这一句的描写。(Please pay attention to the description of this sentence.) Can anyone paraphrase this sentence?"

Here, the teacher used the Chinese switching to get the students' attention. She emphasized what she thought to be important by inserting a Chinese sentence

3b) Teachers' Code-Switching to Build Solidarity with Students

Teachers' code-switching to L1 can be used as the strategy of solidarity building by expressing emotions and affective communication between teachers and students, and it actually contributes to a supportive language environment. Both the words "curious" and "nervous" can be used to describe the students' psychological movement when they learn new knowledge or receive unfamiliar information. Teachers' code-switching to L1 has a potentially positive effect on reducing students' nervousness or fear [16].

\section{Example 7}

T: "Have you read or heard of Great Expectations?"

S: "Sorry, I don't know this book."

T: “It's written by Charles Dickens. It's 远大前程 (the Chinese version of Great Expectations by Charles Dickens)."

In this example, the student felt nervous, as he didn't know the book. The teacher switched to Chinese to build solidarity and give support to the student.

\section{Example 8}

T:"Now, let's review what we have learned last time. Who wrote The Joys of Writing?"

\section{S: (Silence. He looks nervous).}

$\mathrm{T}$ : “不着急, 慢慢来。(Take it easy.) He was the prime minister of Britain. 好好想一想。(Think it over).”

\section{S: "Ah, Winston Churchill!"}

T: "Good. You're right."

Here, when the teacher asked the question, the student was so nervous and anxious that he didn't know how to answer the question. He was scared of being criticized. Instead of reminding him solely in English, the teacher consciously switched to Chinese to encourage the student and help him build his confidence.

\section{3c) Teachers' Code-Switching to Manage Class}

The ways in which the teacher organizes the class also involve a choice of language. Some teachers resorted to L1 after having tried in vain to get the activity going in L2 [13]. The samples also indicate that the teachers tended to manage the class by resorting to Chinese.

\section{Example 9}

T: “Now, it's time for class. 不要讲话了。(Be silent.)"

\section{Example 10}

T: (asked a student to answer the question) "What does this sentence mean?"

\section{S: (Silence)}

T: "Could you paraphrase this sentence?"

S: Sorry.

T: (go to the student nearer) You forgot to take the reading stuff? 下次记着带阅读材料。( Please remember to take the reading stuff the next time).

When the students did something that violated classroom discipline, the teachers tended to switch to Chinese for criticism and maintenance of discipline. The teachers' displeasure expressed in Chinese seemed to be more serious threat.

\section{Example 11}

T: “OK, everybody, next I'll divide you into several groups so that you could work together to finish this oral exercise. 第一排为第一组，第二排为第二组，第三排为第三组...

(The first row will be the first group, and the second row the second group, and the third row the third group...)"

To give directions to activities, the teacher switched to Chinese for the arrangement of the students. Because using Chinese directions would be concise and save a lot of time in managing the class.

3d) Teachers' Code-Switching to Facilitate Students' Understanding

Sometimes, the teachers switched to Chinese to facilitate students' understanding and this usually occurred in the discussion of some grammatical points or vocabulary items.

\section{Example 12}

T: "Attention, class. Please look at this sentence. (Read the sentence) 'To avoid the various foolish opinions to which mankind are prone, no superhuman genious is required.' 'Prone' is a new word and it means 有倾向的. (having the 
probability) 请大家写下这个词并记住。(Please write down this word and try to remember it.) 跟我读。(Please read after me now)."

In this example, the teacher switched to Chinese to instruct the class on the new word "prone", and then asked the students to write down the word and read the word after her.

\section{Example 13}

T: "Let's take one sentence for example for the use of subjunctive mood. 'One would think he had seen a ghost.' 本句使用would, 表示虚拟。(With 'would' in it, this sentence expresses subjunctive mood)."

\section{Example 14}

T: "Later the horrible realization comes to him that the Morlocks live on Eloi meat, carrying off their victims at night. 这里的that引导一个同位语从句。(The word 'that' introduces an appositive clause).”

Many students, esp. non-English-major students, are not very familiar with the terms of English grammar. If the teachers use grammatical terms in English to explain the complicated sentence structure, he is running the risk of creating additional problems with the students' understanding and adding to the length of the lesson.

The above analysis shows that teachers' switching to L1 as an adaptation to communicative needs is rather complicated as it depends on communicative or pedagogical goals.

So far, we have discussed the three categories to which teachers' switching to L1 in the classroom adapt to. The three categories are rich in contents and are never definitely clear-cut [5]. Overlap exists in some cases and there are noticeable difficulties in categorizing code-switching according to the three adaptation categories. In addition, what has been discussed is likely to be incomplete and imperfect, since there might be other cases to be studied and other categories identified in the future.

\section{DISCUSSION}

The present paper attempted to explain teachers' codeswitching in EFL classroom from pragmatic perspective. When teachers engage in the process of teaching, they have specific teaching and communicative goals, either from information exchange or for affective communication. In order to realize or approach these communicative or pedagogical goals, they have to make a choice about which language to use. Code-switching is an important linguistic strategy for bilinguals. The reason why the teacher chooses codeswitching to realize communicative or pedagogical goals is for one of at least three broad reasons: adapt to the linguistic reality, accommodate teachers' and students' language proficiency, and fulfill particular communicative needs.

\section{CONCLUSION}

In the present paper, the adaptability of teachers' switching to L1 is analyzed on the basis of Verschueren's Linguistic Adaptation Theory. The data support the suggestion that teachers' performance of code-switching is mainly from the three elements of adaptation to the linguistic reality, teachers' and students' language proficiency, and communicative needs in the process of achieving their communicative goals. Thus, teachers' code-switching is more than simply a linguistic behavior; it is a realization of dynamic adaptation to the situation and appears to be carried out in accordance with the Adaptation Principle.

\section{REFERENCES}

[1] Auer P, Ed. Code-switching in conversation: language, interaction and identity. London: Routledge 1998.

[2] Poplack S. Sometimes I'll start a sentence in Spanish y termino en Espanol: Toward a typology of code-switching. Linguistics 1980; 18: 581-616.

[3] Cook V. Using the first language in the classroom. Can Mod Lang Rev 2001; 57: 402- 23.

[4] Verschueren J. Understanding pragmatics. London: Edward Arnold 1999.

[5] Yu GD. The study from the pragmatic perspective on English/Chinese code-switching. Shanxi: Shanxi People's Press 2001.

[6] Guthrie EML. Six cases in classroom communication: A study of teacher discourse in the foreign language classroom. In: Lantolf JP, Labarca A, Eds. Research in second language learning: Focus on the classroom. Norwood, NJ: Ablex 1984.

[7] Skinner D. Access to meaning: The anatomy of the language/learning connection. Multiling Multicult Dev 1985; 6: 369 89.

[8] Hegen S. Language policy and strategy issues in the new Europe. J Lang 1992; 25: 23-5.

[9] Polio CG, Duff PA. Teachers' language use in university foreign language classrooms: A qualitative analysis of english and target language alternation. J Mod Lang 1994; 78: 313-26.

[10] Rolin-Ianziti J, Brownlie S. Teacher use of learners' native language in the foreign language classroom. Can Mod Lang Rev 2002; 58: 402-26.

[11] Lin A. Teaching in two tongues: Language alternation in foreign language classrooms. Doctoral Thesis. Hong Dong City Polytechnic 1990: Available from: http://www.cnki.net/index.htm

[12] Wang L. Teachers' Chinese/English code-switching in classroom: An adaptation approach. Master Thesis. Shanxi University 2003: Available from: http://www.cnki.net/index.htm

[13] Macaro E. Target language, collaborative learning and autonomy. Clevedon: Multilingual Matters 1997.

[14] Storch N, Wiggleworth G. Is there a role for the use of the L1 in an L2 setting? TESOL Q 2003; 37: 760-70.

[15] Chaudron C. Second language classrooms: Research on teaching and learning. Cambridge: Cambridge University Press 1988.

[16] Mao L. An analysis of college English teachers' Chinese and English code-switching in class. Master Thesis. Dongbei Fanancial University 2007: Available from: http://www.cnki.net/index.htm 